\title{
Distinct Neuronal Interactions in Anterior Inferotemporal Areas of Macaque Monkeys during Retrieval of Object Association Memory
}

\author{
Toshiyuki Hirabayashi, Keita Tamura, Daigo Takeuchi, Masaki Takeda, Kenji W. Koyano, and Yasushi Miyashita \\ Department of Physiology, The University of Tokyo School of Medicine, Tokyo 113-0033, Japan
}

In macaque monkeys, the anterior inferotemporal cortex, a region crucial for object memory processing, is composed of two adjacent, hierarchically distinct areas, TE and 36, for which different functional roles and neuronal responses in object memory tasks have been characterized. However, it remains unknown how the neuronal interactions differ between these areas during memory retrieval. Here, we conducted simultaneous recordings from multiple single-units in each of these areas while monkeys performed an object association memory task and examined the inter-area differences in neuronal interactions during the delay period. Although memory neurons showing sustained activity for the presented cue stimulus, cue-holding $(\mathrm{CH})$ neurons, interacted with each other in both areas, only those neurons in area 36 interacted with another type of memory neurons coding for the to-be-recalled paired associate (pair-recall neurons) during memory retrieval. Furthermore, pairs of $\mathrm{CH}$ neurons in area TE showed functional coupling in response to each individual object during memory retention, whereas the same class of neuron pairs in area 36 exhibited a comparable strength of coupling in response to both associated objects. These results suggest predominant neuronal interactions in area 36 during the mnemonic processing, which may underlie the pivotal role of this brain area in both storage and retrieval of object association memory.

Key words: associative object memory; cell assembly; coherence; inferior temporal cortex; macaque monkey; multiple single-unit recordings

\section{Introduction}

The anterior inferotemporal (AIT) cortex of primates is located at the final stage of the ventral visual pathway and is thought to be a "storehouse" of object memory (Squire and Zola-Morgan, 1991; Logothetis and Sheinberg, 1996; Mishkin et al., 1997; Miyashita, 2004). Previous single-unit studies have identified memory neurons coding for the learned objects or their associations in this brain region (Miyashita, 1988; Erickson and Desimone, 1999; Messinger et al., 2001). The AIT cortex is composed of two adjacent, hierarchically distinct areas, areas TE and 36 (Suzuki and Amaral, 1994; Saleem and Tanaka, 1996). Both lesion studies (Buckley et al., 1997; Buffalo et al., 1999) and single-unit studies (Xiang and Brown, 1998; Liu and Richmond, 2000; Naya et al., 2003a; Naya et al., 2003b) have demonstrated functional differences between these areas in the mnemonic processing (Suzuki, 2010). However, it remains unknown how the neuronal interac-

\footnotetext{
Received Feb. 12, 2014; revised May 2, 2014; accepted June 7, 2014.

Author contributions: T.H. and Y.M. designed research; T.H., K.T., and D.T. performed research; T.H. contributed unpublished reagents/analytic tools; T.H. and Y.M. analyzed data; T.H., K.T., D.T., M.T., K.W.K., and Y.M. wrote the paper.

This work was supported by MEXT/JSPS KAKENHI (Grants 19002010 and 24220008 to Y.M.), CREST, Japan Science and Technology Agency (Y.M.), Takeda Science Foundation (Y.M.), and by MEXT (Grants-in-Aid for Young Scientists B 25870142 to T.H. and 25830001 to K.W.K.). We thank H. Kasahara and T. Watanabe for experimental assistance. The authors declare no competing financial interests.

Correspondence should be addressed to Toshiyuki Hirabayashi, Department of Physiology, The University of Tokyo School of Medicine, 7-3-1 Hongo, Bunkyo-ku, Tokyo 113-0033, Japan. E-mail: thirabay@m.u-tokyo.ac.jp. DOI:10.1523/JNEUROSCI.0600-14.2014

Copyright $\odot 2014$ the authors $\quad 0270-6474 / 14 / 349377-12 \$ 15.00 / 0$
}

tions differ between these areas during memory retrieval. A recent study demonstrated that, in area 36, information flows from neurons coding for the presented cue stimulus, cue-holding $(\mathrm{CH})$ neurons, to another type of neurons coding for the to-berecalled paired-associate, pair-recall (PR) neurons, during memory retrieval (Hirabayashi et al., 2013b; Hirabayashi and Miyashita, 2014). Both CH and PR neurons have also been observed in area TE (Naya et al., 2001; Naya et al., 2003b), so these single-unit activities predict that similar interactions between memory neurons are also found in area TE. However, another possibility is that functional coupling between $\mathrm{CH}$ and PR neurons can be observed only in area 36 and, if this is the case, then it would suggest a unique role of the microcircuit operation in area 36 in the mnemonic processing. To test these possibilities, we conducted simultaneous recordings from multiple single-units in areas TE and 36 while monkeys performed an object association memory task (Sakai and Miyashita, 1991; Naya et al., 2001; Takeuchi et al., 2011; Hirabayashi et al., 2013a, 2013b) and examined the inter-area differences in the microcircuit operations during memory retrieval. The results demonstrated that only the $\mathrm{CH}$ neurons in area 36 , but not in area TE, interacted with PR neurons during memory retrieval. Furthermore, only pairs of $\mathrm{CH}$ neurons in area 36 exhibited functional coupling in response to a learned association of objects during memory retention. These inter-area differences in the neuronal coupling were not explained by the firing rates of the constituent neurons and supported the latter hypothesis. 


\section{Materials and Methods}

Subjects. All animal procedures complied with the National Institutes of Health Guide for the Care and Use of Laboratory Animals and were approved by the Institutional Review Committee of the University of Tokyo School of Medicine. The subjects were two adult male macaque monkeys, Macaca mulatta (Monkey 1) and Macaca fuscata (Monkey 2), weighing 6-8 kg. A head holder and recording chamber for electrophysiological recordings were attached to the skull under standard aseptic, anesthetic, and postoperative treatment protocols (anesthetic: sodium pentobarbital, $3 \mathrm{mg} / \mathrm{kg} / \mathrm{h}$, i.v., and xylazine, $2 \mathrm{mg} / \mathrm{kg}$, i.m., supplemented as needed; analgesic: acetaminophen, $20 \mathrm{mg} / \mathrm{kg} / \mathrm{d}$, p.o.; prophylactic antibiotic: ampicillin, 100 mg/kg/d, i.m.; Matsui et al., 2007; Takeuchi et al., 2011; Hirabayashi et al., 2013a, 2013b). Blood pressure, heart rate, oxygen saturation, and respiration rate were measured continuously throughout the surgeries to monitor the animal's condition carefully and xylocaine was injected locally when needed. After the surgery, the animal was monitored in the home cage at least for a week to allow full recovery from the surgery.

Behavioral task. The procedure for the pair-association memory task (see Fig. $1 A, B$ ) was described previously in detail (Naya et al., 2003a; Yoshida et al., 2003; Takeuchi et al., 2011; Hirabayashi et al., 2013a, 2013b). In brief, the monkeys were trained to perform an object-object association memory task using a set of 6 pairs of visual stimuli ( 12 monochrome Fourier descriptors) extending $\sim 5^{\circ} \times 5^{\circ}$ (see Fig. $1 B$ ). In some of the experiments with Monkey 2, five of the six pairs of stimuli were used. The monkeys were trained for several months to learn all of the stimulus pairings. The stimuli were presented on a monitor (refresh rate: $60 \mathrm{~Hz}$ ) using custom-made software written in C. In each trial, a fixation point $\left(0.2^{\circ}\right.$ in size) was presented for $0.8 \mathrm{~s}$, after which a cue stimulus ( 1 of the 12 visual stimuli) was presented for $1 \mathrm{~s}$. After a $2.2 \mathrm{~s}$ delay period, 2 stimuli were presented: the paired associate of the cue stimulus and a distractor. The monkeys obtained fruit juice as a reward for correctly touching the paired associate (Monkey 1 ) or pressing the corresponding button (Monkey 2) within $1.5 \mathrm{~s}$. Throughout the recording sessions after training, the monkeys' performance was $>90 \%$ correct. Eye position was monitored using a scleral search coil (Judge et al., 1980; Tomita et al., 1999; Hirabayashi and Miyashita, 2005; Hirabayashi et al., 2010, 2013a, 2013b). If the eye position deviated $>1.5-2.0^{\circ}$ from the fixation point before the end of the delay period, then the trial was automatically terminated.

Recording procedures. Multiple single-unit activities were recorded from each of areas TE and 36 of the AIT cortex in four hemispheres of the two monkeys using a multicontact electrode (Tetrode; Thomas Recording; Hirabayashi and Miyashita, 2005; Hirabayashi et al., 2010; Ohiorhenuan et al., 2010; Hirabayashi et al., 2013a, 2013b). Neuronal mapping was conducted first to identify the regions where stimulus-selective neurons were densely located, and these regions corresponded well with those observed in previous studies (Naya et al., 2003a; Yoshida et al., 2003). Neuronal activities in the present dataset were then recorded in each of these regions with a multicontact electrode. The resultant coordinates of the recording region for data acquisition (see Fig. 1C) in area 36 were $\sim 18-21 \mathrm{~mm}$ anterior to the interaural line and 11-14 mm lateral to the midline for Monkey 1 and $20-23 \mathrm{~mm}$ anterior to the interaural line and 11-14 mm lateral to the midline for Monkey 2. Likewise, the coordinates of the recording region for data acquisition in area TE were $\sim 18-21 \mathrm{~mm}$ anterior to the interaural line and $18-21 \mathrm{~mm}$ lateral to the midline for both monkeys. In the multiple single-unit recordings, neuronal signals were amplified, band-pass filtered $(250 \mathrm{~Hz}$ to $5 \mathrm{kHz})$, and sorted online into pairs of single-units using a standard window discrimination technique to monitor the responses of recorded neurons. The neuronal signals were also stored, digitized offline at $25 \mathrm{kHz}$, and then subjected to waveform analyses to more precisely sort into multiple single-units (Usrey et al., 2000; Roy and Alloway, 2001; Hirabayashi and Miyashita, 2005; Lee et al., 2005; Hirabayashi et al., 2013a, 2013b). The presence of a refractory period was confirmed in the autocorrelogram for each unit (Usrey et al., 2000; Hirabayashi and Miyashita, 2005; Takeuchi et al., 2011; Hirabayashi et al., 2013a, 2013b). If the number of spikes with interspike intervals $<2 \mathrm{~ms}$ exceeded $1 \%$ of the total for a given unit, then that unit was discarded or reisolated (Hirabayashi and Miyashita, 2005; Takeuchi et al., 2011; Hirabayashi et al., 2013a, 2013b). Cross-cluster interspike interval histograms for each pair of units were also confirmed to show no artificial peaks that would imply the false sorting of spikes from one cell into two different clusters. In total, 201 single-units (126 and 75 for Monkeys 1 and 2, respectively) were isolated in 38 recording sessions for area TE (23 and 15 sessions for Monkeys 1 and 2, respectively) and 183 single-units (82 and 101 for Monkeys 1 and 2, respectively) were isolated in 39 recording sessions for area 36 (16 and 23 for Monkeys 1 and 2, respectively). These offline-sorted spike data obtained for correct trials were further analyzed for responses and functional connectivity. Waveform analyses were conducted to separate the recorded single-units into regular spiking, putative excitatory pyramidal neurons that exhibited relatively broad waveforms with a valley-to-peak times longer than $0.3 \mathrm{~ms}$ and fast-spiking, putative inhibitory interneurons that exhibited relatively narrow waveforms with a valley-to-peak time shorter than $0.25 \mathrm{~ms}$ (Mitchell et al., 2007; Woloszyn and Sheinberg, 2012). The resultant valley-to-peak lengths were $0.44 \pm 0.08 \mathrm{~ms}$ (mean \pm $\mathrm{SD})$ and $0.19 \pm 0.03 \mathrm{~ms}$ for the regular-spiking and fast-spiking neurons, respectively.

Functional coupling between single neurons. In the present study, functional coupling between single neurons was evaluated using coherence, which provides a normalized spectral estimate of cross-correlation between two time series. Coherence is the magnitude of coherency, which is the cross-spectrum between two time series normalized by the autospectra. Spectral estimates of spike trains were calculated using a multitaper method (Jarvis and Mitra, 2001; Pesaran et al., 2002; Buschman and Miller, 2007; DeCoteau et al., 2007; Fries et al., 2008; Pesaran et al., 2008; Zhou et al., 2008; Gregoriou et al., 2009; Jutras et al., 2009; Bokil et al., 2010; Hirabayashi et al., 2010; Lima et al., 2011; Verhoef et al., 2011; Saalmann et al., 2012; Salazar et al., 2012; Hirabayashi et al., 2013b) with Chronux, an open-source software package (RRID: nif-0000-00082; http://chronux.org/; Pesaran et al., 2008; Zhou et al., 2008; Bokil et al., 2010; Hirabayashi et al., 2010; Lima et al., 2011; Saalmann et al., 2012; Salazar et al., 2012; Hirabayashi et al., 2013b) implemented in MATLAB (RRID: nlx_153890; The MathWorks). With this method, spectral estimates of spike trains were determined as the average of the results computed after multiplying several different taper functions by the original signal. These processes yield less biased and less noisy spectral estimates than conventional methods (Jarvis and Mitra, 2001; Fries et al., 2008; Bokil et al., 2010). Orthogonal Slepian tapers were applied to calculate the spectral estimates of spike trains that were downsampled to $1 \mathrm{kHz}$ (see Coherence analysis for pairs of stimulus-selective memory neurons, below, for the number of tapers used)

Coherence analysis for pairs of stimulus-selective memory neurons. To calculate the coherence between stimulus-selective memory neurons, the spiking response of each single-unit was examined as follows (Hirabayashi et al., 2013a, 2013b). A given single-unit was defined as cue selective if the cue activity (mean firing rate during a $900 \mathrm{~ms}$ period beginning $100 \mathrm{~ms}$ after cue onset) was significantly stimulus selective (one-way ANOVA, $p<0.05$ ). Similarly, a given single-unit was defined as delay selective if the delay activity (mean firing rate during a $1700 \mathrm{~ms}$ period beginning $500 \mathrm{~ms}$ after cue offset) showed significant stimulus selectivity (one-way ANOVA, $p<0.05$ ). In total, 121 neurons in area TE (86 and 35 for Monkeys 1 and 2, respectively) and 112 neurons in area 36 (65 and 47 for Monkeys 1 and 2, respectively) exhibited both cueselective and delay-selective responses (CD-selective cells) and were included in the main analyses in the present study. For a given CD-selective cell, neuronal activity elicited by a given stimulus was classified as $\mathrm{CH}$ when: (1) the neuron showed significant cue activity in response to that stimulus, which was detected as a significant increase in firing rate compared with the preceding baseline period $(800 \mathrm{~ms}$ before cue onset; paired $t$ test, $p<0.05$ ) and (2) the delay activity elicited by that stimulus was less than the activity during the cue period (see Fig. 3, green). Likewise, for a given CD-selective cell, neuronal activity elicited by a given stimulus (c-stimulus) was classified as PR when: (1) the response to the paired associate of the c-stimulus was significantly larger than the baseline activity and significantly larger than the response to the c-stimulus (paired $t$ test, $p<0.05$ ) and (2) the delay activity elicited by the 
A

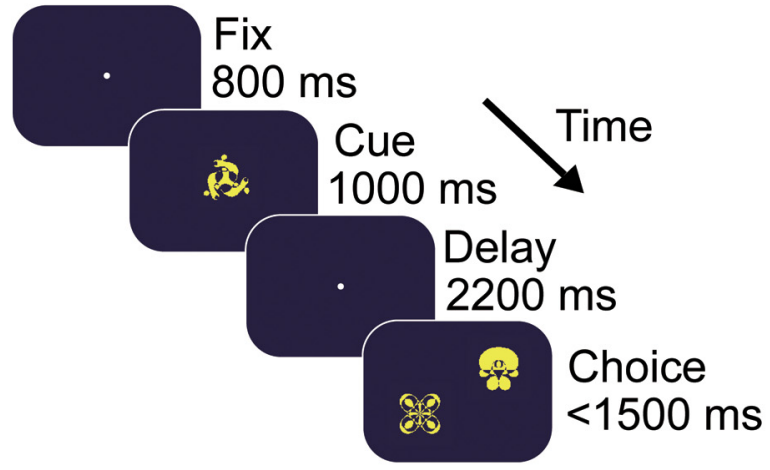

B

Learned object pairs

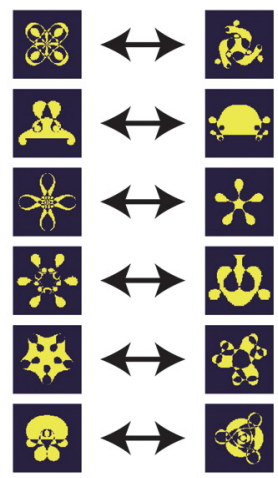

C
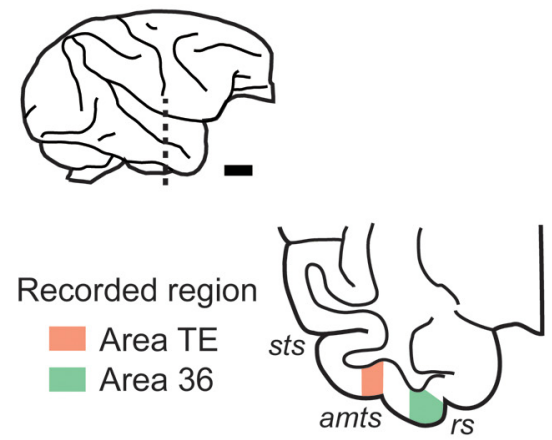

D

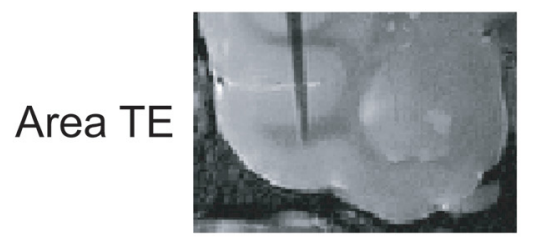

Area 36

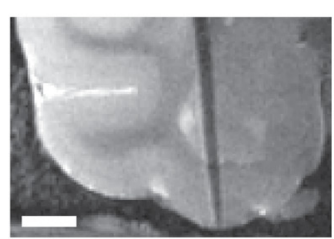

Figure 1. Behavioral task and recording sites. $\boldsymbol{A}$, Procedure of an object association memory task. $\boldsymbol{B}$, Learned pairs of objects for Monkey 1. C, Recording regions. Top, Lateral view of a monkey brain. Scale bar, $10 \mathrm{~mm}$. Bottom, coronal view at the level indicated by the dotted line in the lateral view. D, Magnetic resonance (MR) images showing a electrode penetrated in the recorded region in area TE (top) and area 36 (bottom) of a monkey. Scale bar, $5 \mathrm{~mm}$. High-resolution MR images were obtained using a 4.7 T MR imaging scanner with a $T_{2}$-weighted fast spin echo sequence (repetition time, $3000 \mathrm{~ms}$; echo time, $60 \mathrm{~ms}$; matrix size, $256 \times 256$; voxel size, $200 \times 200 \times 1000 \mu \mathrm{m}^{3}$; Matsui et al., 2007). Note that the diameter of the microelectrode is enhanced due to magnetic susceptibility (Matsui et al., 2007).

c-stimulus was greater than the activity during the cue period just before the delay period (see Fig. 3, blue). A significant majority of delay activities in our database in both areas were greater than the baseline activity $(\mathrm{CH}$, $84 / 112(75 \%)$ and $80 / 107(75 \%)$ in areas TE and 36, respectively, $p<$ $0.001, \chi^{2}$ test; PR, 52/56 (93\%) and 52/59 (88\%) in areas TE and 36, respectively, $p<0.001)$.

For a given cell pair, coherence was calculated for a given stimulus if the response of each constituent cell for that stimulus was classified as $\mathrm{CH}$ or PR; that is, $\mathrm{CH}$ and/or PR activities of both constituent cells of a pair were required for the same stimulus. In total, $54 \%$ and $46 \%$ of CDselective cell pairs were not included in the coherence analyses in areas TE and 36, respectively, because the stimulus selectivities did not match up between the constituent cells. For each neuron pair, if more than two stimuli were classified as candidates for calculating the coherence for a given pair category of memory neurons (i.e., $\mathrm{CH}-\mathrm{CH}, \mathrm{CH}-\mathrm{PR}$, or PR$\mathrm{PR}$ ), then the product of the delay responses of both the constituent neurons was calculated for each of these stimuli to determine the optimal stimulus that elicited the largest response from both neurons. Unless stated otherwise, the resultant optimal stimulus for each cell pair was then used to calculate the coherence in the present study. Spike trains were obtained for $91 \pm 4$ (mean \pm SEM) trials for each stimulus to calculate the trial average of coherence and spike power. For each cell pair, a trial-shifted control (Lee, 2003; Brovelli et al., 2004; Saalmann et al., 2007; Zhou et al., 2008; Hirabayashi et al., 2010; Salazar et al., 2012;
Hirabayashi et al., 2013b) was subtracted from the coherence calculated using raw spike trains and the resultant value of coherence was evaluated in each task epoch (baseline, $-800-0$ ms; cue, 100-1000 ms, delay, 1500-2500 ms from cue onset, respectively). The spectral dynamics of coherence (see Fig. 2C) was calculated using a $500 \mathrm{~ms}$ sliding window that was slid in 50 ms steps (Hirabayashi et al., 2013b). The strength of coherence and spike power in a given frequency range was defined as the average value in the corresponding frequency range [gamma, 30-130 Hz (Tallon-Baudry et al., 2005; Hirabayashi et al., 2013b; Ojemann et al., 2013); beta, 15-25 Hz (Ward, 2003; Lee et al., 2013); alpha, 8-12 Hz (Lee et al., 2005; Bollimunta et al., 2008; Lima et al., 2011; Lashgari et al., 2012; Hirabayashi et al., 2013a); theta, 5-8 Hz (Vyazovskiy and Tobler, 2005; Jensen and Colgin, 2007)]. In the calculations of coherence and spike power spectrum, seven tapers were used for the gamma frequency range and three tapers were used for the lowerfrequency ranges (i.e., beta, alpha, and theta). Spike power spectrum of each neuron (see Fig. $7 C$ ) was normalized by the firing rate (Pesaran et al., 2002; Joelving et al., 2007; Lima et al., 2011).

Phase consistency of the coherence (see Fig. $7 A, B$ ) was evaluated for each cell pair using the jackknife estimate of the confidence interval (2 SDs) for coherence phase across different trials and tapers (Jarvis and Mitra, 2001; Pesaran et al., 2002; Bokil et al., 2010; Lima et al., 2011). The jackknife estimate of the coherence phase was calculated for each cell pair at the frequency where the coherence of the cell pair was the maximum in the gamma range. Note that the peak frequency of the coherence for a given cell pair was calculated for both raw and trialshifted spike trains independently to compare the resultant phase consistency between these conditions.

Statistics. Unless stated otherwise, all statistical tests in the present study were two-sided.

\section{Results}

We trained two macaque monkeys to perform an object association memory task in which they had to retrieve a long-term visual memory in response to a presented cue stimulus (Fig. $1 A, B$; Sakai and Miyashita, 1991; Tomita et al., 1999; Naya et al., 2001; Takeda et al., 2005; Takeuchi et al., 2011; Hirabayashi et al., 2013a, 2013b). Then, we conducted simultaneous recordings from multiple single-units by inserting a multicontact electrode (Hirabayashi and Miyashita, 2005; Hirabayashi et al., 2010; Ohiorhenuan et al., 2010; Hirabayashi et al., 2013a, 2013b) in areas TE and 36 of the AIT cortex (Fig. 1C,D) while the monkeys performed the object-association memory task. We recorded from 191 regular-spiking, putative pyramidal neurons (120 and 71 for Monkeys 1 and 2, respectively) in 38 recording sessions for area TE (23 and 15 for Monkeys 1 and 2) and 174 regular-spiking, putative pyramidal neurons (78 and 96 for Monkeys 1 and 2) in 39 recording sessions for area 36 ( 16 and 23 for Monkeys 1 and 2). Neuronal activities were classified as CH (Naya et al., 2003b; Osada et al., 2008; Hirabayashi et al., 2013b) when a given neuron showed cue activity and subsequent decreasing delay activity selectively in response to a given stimulus and as PR (Sakai and 
Miyashita, 1991; Naya et al., 2001; Naya et al., 2003b; Osada et al., 2008; Hirabayashi et al., 2013b) when a given neuron exhibited increasing delay activity selectively in response to a given stimulus as well as selective cue activity in response to its paired associate (see Materials and Methods).

\section{Neuronal responses and functional coupling in the AIT cortex}

Figure 2 shows functional coupling between a pair of simultaneously recorded memory neurons in area 36. During the delay period, both neurons of this pair exhibited prominent $\mathrm{CH}$ activity: stimulusselective cue activity was evoked by the presentation of their optimal stimulus and was followed by decreasing but substantial activities during the subsequent delay period (Fig. 2A). Both neurons exhibited selective responses to their optimal stimulus during both the cue and delay periods (Fig. 2B). Functional coupling between these neurons was determined by calculating coherence between the spiking activities (Jarvis and Mitra, 2001; Lee, 2003; Fries et al., 2008; Sirota et al., 2008; Zhou et al., 2008; Gregoriou et al., 2009; Hirabayashi et al., 2010; Lima et al., 2011; Verhoef et al., 2011; Hirabayashi et al., 2013b). The dynamics of the coherence spectrum of this cell pair calculated for the optimal stimulus is shown in Figure 2C. Prominent coherence was observed during both the cue and delay periods mostly in the gamma frequency range $(30-130 \mathrm{~Hz})$.

The $\mathrm{CH}$ and PR activities of the neuronal populations recorded in areas TE and 36 are shown in Figure 3. In both areas, $\mathrm{CH}$ neurons showed significant responses to the optimal stimulus both during the cue and delay periods ( $p<0.001$ vs baseline, paired $t$ test; $n=112$ and 107 for areas TE and 36, respectively; Fig. $3 A, B$, green), but not to the worst stimulus. In contrast, PR neurons did not respond to the optimal stimulus during the cue period, but exhibited prominent responses during the subsequent delay period ( $p<0.001, n=56$ and 59 for areas TE and 36, respectively; Fig. $3 A, B$, blue) in a stimulus-dependent manner. We next investigated whether the neuronal coupling during the cue period could be observed regardless of the delay activities of the constituent neurons (Fig. 4). Pairs of $\mathrm{CH}$ neurons in both areas TE and 36 exhibited a prominent increase in gamma coherence for their optimal stimulus compared with the baseline ( $p<0.001$, two-way repeated-measures ANOVA followed by LSD test, $n=70$ and 55 for areas TE and 36, respectively). In contrast, this gamma coherence was not observed for pairs of neurons exhibiting stimulus-selective responses only during the cue period (cue-selective with no delay activity neurons: $p>0.8$, $n=20$ and 16 for areas TE and 36, respectively). These results suggest that functional coupling, even during the cue period, was -250 to $250 \mathrm{~ms}$ after cue onset.
B Cue Delay
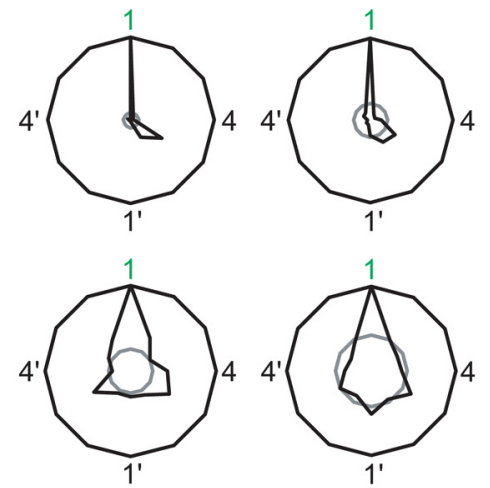

Norm. Response profile

Time from cue onset (ms)

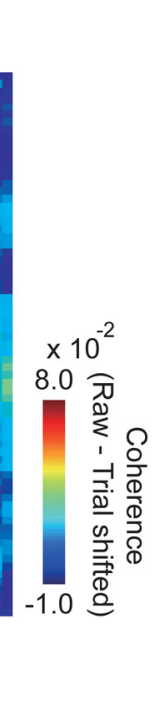

Time from cue onset (ms)

Figure 2. Functional coupling between a pair of simultaneously recorded memory neurons in the AIT cortex. A, Response dynamics of the cell pair. Green traces indicate the response to the optimal stimulus for the cell pair (see Materials and Methods). of each neuron during the cue (left) and delay (right) periods. Each vertex of a given plot corresponds to each stimulus (1-6), with the opposite side depicting the paired associate $\left(1^{\prime}\right.$ to $\left.6^{\prime}\right)$. The top vertices depict the optimal stimulus. Gray circles are the respectively. C, Dynamics of the coherence spectrum of the cell pair calculated for the optimal stimulus. Trial-shifted control (see Materials and Methods) was subtracted. Vertical white lines depict the cue onset and offset. Time 0 indicates the window from

predominantly observed between neurons showing stimulusselective delay activities.

\section{Inter-area differences in functional coupling among memory neurons}

To investigate the operation of memory circuits at the population level, coherence between pairs of memory neurons (i.e., $\mathrm{CH}-\mathrm{CH}$, $\mathrm{CH}-\mathrm{PR}$, and PR-PR) was then calculated in areas TE and 36 for their optimal stimulus. During the cue period, an increase in gamma coherence from the baseline was only observed for $\mathrm{CH}-\mathrm{CH}$ pairs in both areas $(p<0.001$ for both areas TE and 36, compared with the baseline, two-way repeated-measures ANOVA followed by LSD, $n=70$ and 55, respectively; Fig. 5, top). During the subsequent delay period, $\mathrm{CH}-\mathrm{CH}$ pairs retained this increase in gamma coherence in both areas $(p<0.02$ and $p<$ 0.009 for areas TE and 36, respectively). In contrast, gamma co- 


\section{Population average responses of memory neurons}

A Area TE

Cue

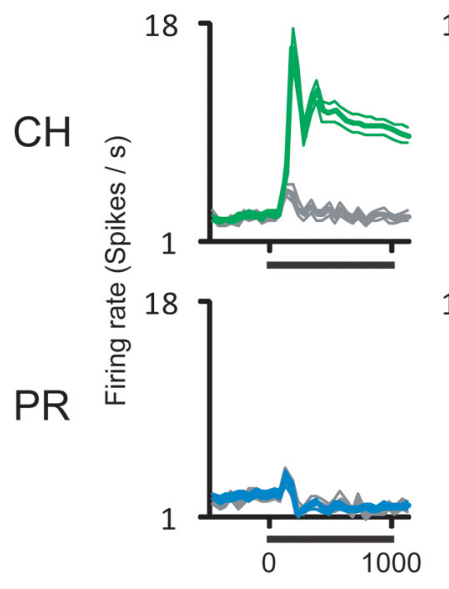

B
Area 36

Delay
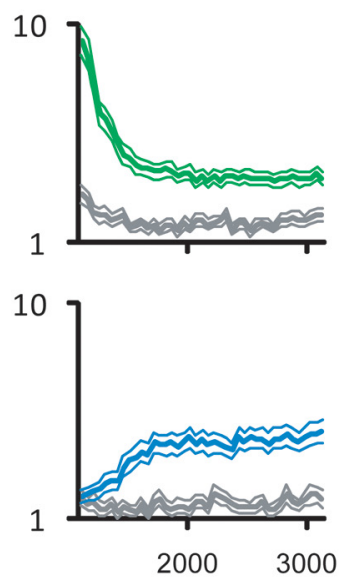

Cue

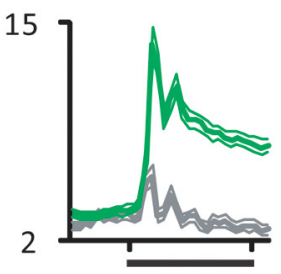

15

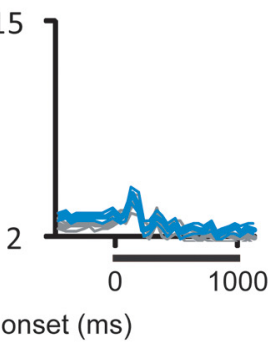

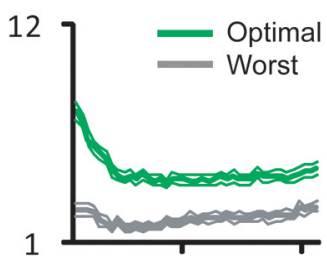

12

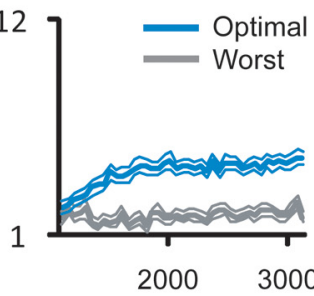

Time from cue onset (ms)

Area TE

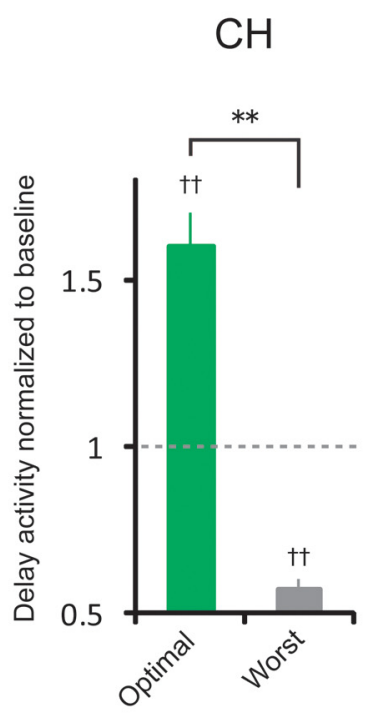

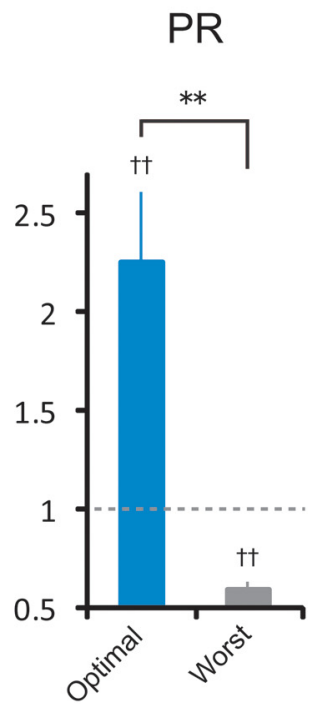

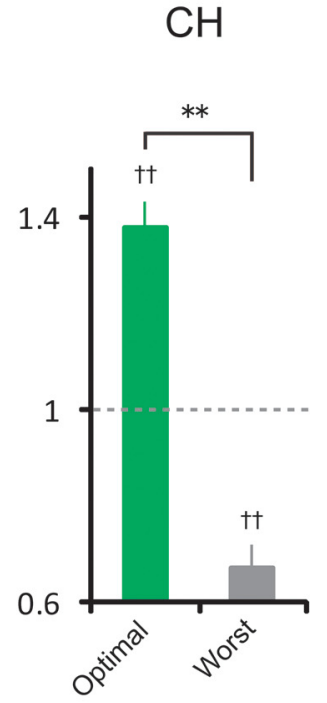

Area 36

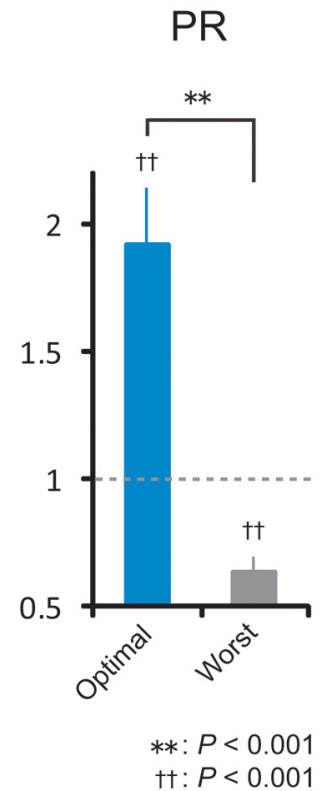

Figure 3. Population average responses of memory neurons in areas TE and 36 of the AlT cortex. A, Population response dynamics of (CH (green) and PR (blue) neurons for the optimal stimulus (see Materials and Methods) in areas TE (left) and 36 (right). Gray traces are the worst responses. Thick and thin traces are the mean and mean \pm SEM, respectively. Horizontal black bars depict the cue period. $\boldsymbol{B}$, Delay activity of memory neurons normalized to the baseline. ††Comparison with the baseline. Error bars indicate SEM.

herence of $\mathrm{CH}-\mathrm{PR}$ and $\mathrm{PR}-\mathrm{PR}$ pairs emerged during the delay period only in area $36(p<0.005$ and $p<0.04$ for $\mathrm{CH}-\mathrm{PR}$ and PR-PR pairs, $n=54$ and 22, respectively), but not in area TE ( $p>$ 0.8 and $p>0.3$ for CH-PR and PR-PR pairs, $n=43$ and 24, respectively; Fig. 5, bottom). It should be noted that, during the delay period, PR activities in area TE did not significantly differ from those in area 36 ( $p>0.4$, paired $t$ test) or from $\mathrm{CH}$ activities in area TE $(p>0.3)$. Furthermore, direct comparison of the coherence between these areas revealed that the patterns of functional coupling among the memory neurons were significantly different between these areas during the delay period $(p<0.05$, interaction between factors of "area" and "pair type," two-way ANOVA), but not during the cue period ( $p>0.3$ ). Together, these results indicate that functional coupling was observed between $\mathrm{CH}$ neurons during both the cue and delay periods in both areas, whereas the interactions involving PR neurons emerged during the delay period only in area 36.

One of the prominent functional differences between areas TE and 36 is the representation of learned object associations in the neuronal activity (Naya et al., 2003a; Hirabayashi et al., 2013a). 
To assess the neuronal interactions for learned object associations during the delay period, we calculated gamma coherence between $\mathrm{CH}$ activities for both the optimal stimulus and its paired associate (i.e., the optimal pair of stimuli) in these areas. Although a significant increase in gamma coherence from the baseline was observed only for the optimal stimulus in area TE $(p<0.02$ and $p>0.5$ for the optimal stimulus and its paired associate, respectively, vs baseline, paired $t$ test, $n=$ 70 ), both of these stimuli evoked a significant increase in gamma coherence in area $36(p<0.006$ and $p<0.05, n=55$; Fig. $6)$. Consequently, a significant difference in gamma coherence was observed between the optimal stimulus and its paired associate in area TE $(p<0.02$, paired $t$ test), but not in area $36(p>0.4)$. It should be noted that the difference in the coupling strength for these stimuli observed in area TE was not significantly correlated with the difference in the firing rates (Pearson's $r=0.17, p>0.15$; Spearman's $r=0.14, p>0.24)$. Furthermore, coherence for the optimal stimulus in area TE did not change significantly after random eliminations of spikes to match the firing rates of the constituent neurons with those for the paired associate $(p>$ 0.2 , paired $t$ test; Gregoriou et al., 2009; Verhoef et al., 2011; Dean et al., 2012) and the resultant coherence remained greater than the baseline $(p<0.05)$. These results indicate that whereas $\mathrm{CH}$ neurons in area TE interacted with each other specifically for the optimal stimulus during the delay period, $\mathrm{CH}$ neurons in area 36 were functionally coupled for both stimuli of the optimal pair.

\section{Neuronal interactions in the lower frequency ranges}

Previous studies have shown that oscillatory neuronal activities in the lower frequency ranges are also involved in various cognitive processes (Kahana, 2006; Bollimunta et al., 2008; Pesaran et al., 2008; Bollimunta et al., 2011; Saalmann et al., 2012; Buzsáki and Moser, 2013). We thus investigated whether functional coupling between memory neurons was also present in lower frequency ranges, including theta $(5-8 \mathrm{~Hz}$; Vyazovskiy and Tobler, 2005; Jensen and Colgin, 2007), alpha (8-12 Hz; Lee et al., 2005; Bollimunta et al., 2011; Lima et al., 2011; Lashgari et al., 2012; Hirabayashi et al., 2013b), and beta (15-25 Hz; Ward, 2003; Lee et al., 2013). In both areas, an increase in the low-frequency coherence was only observed during the cue period for $\mathrm{CH}-\mathrm{CH}$ pairs $(p<0.01$, alpha range in area TE, beta range in areas TE and 36, compared with the baseline, two-way repeated-measures ANOVA followed by LSD), but not during the delay period $(p>0.1)$. These results suggest that, during memory retrieval, neuronal coupling in the microcircuit of the AIT cortex was specific to the gamma frequency range, which is consistent with previous studies showing its involvement in local network processing (Fries et al., 2008; Zhou et al., 2008; Hirabayashi et al., 2010).
Phase relation and cell-to-cell specificity of gamma coherence during the delay period

The phase of coherence, which reflects the temporal offset of the coupling between two signals, can provide another measure of functional coupling in addition to the amplitude of the coherence (Womelsdorf et al., 2007). Therefore, we investigated whether the gamma coherence observed during the delay period (for $\mathrm{CH}-\mathrm{CH}$ pairs in area TE and all classes of memory neuron pairs in area 36) was accompanied by the phase consistency (i.e., temporal precision of the interaction) by calculating the phase variance of the coherence across trials and taper functions (see Materials and Methods). The results showed that, for both areas TE and 36, phase variance of the gamma coherence was significantly smaller when calculated with the raw spike trains than when calculated with the trial-shifted spike trains $(p<0.002$ and 0.001 for areas TE and 36, respectively; paired $t$ test; $n=70$ and 131; Fig. $7 A, B$ ). These results suggest that the neuronal coupling observed during the delay period was accompanied by consistent temporal relationships between spikes of memory neurons.

In area 36, all combinations of memory cell classes (i.e., $\mathrm{CH}$ $\mathrm{CH}, \mathrm{CH}-\mathrm{PR}$, and PR-PR) exhibited significant gamma coherence during the delay period (Fig. 5, bottom right). Therefore, to determine the cell-to-cell specificity of these couplings, we next tested whether the observed gamma coherence during the delay period was attenuated when the cell pairings were altered to abolish the common responses to the optimal stimulus. In both areas, when one of the constituent cells was replaced with another cell that showed significant delay activity but for other stimuli, the gamma coherence was significantly reduced ( $p<0.001$, com- 


\section{Functional coupling between memory neurons}
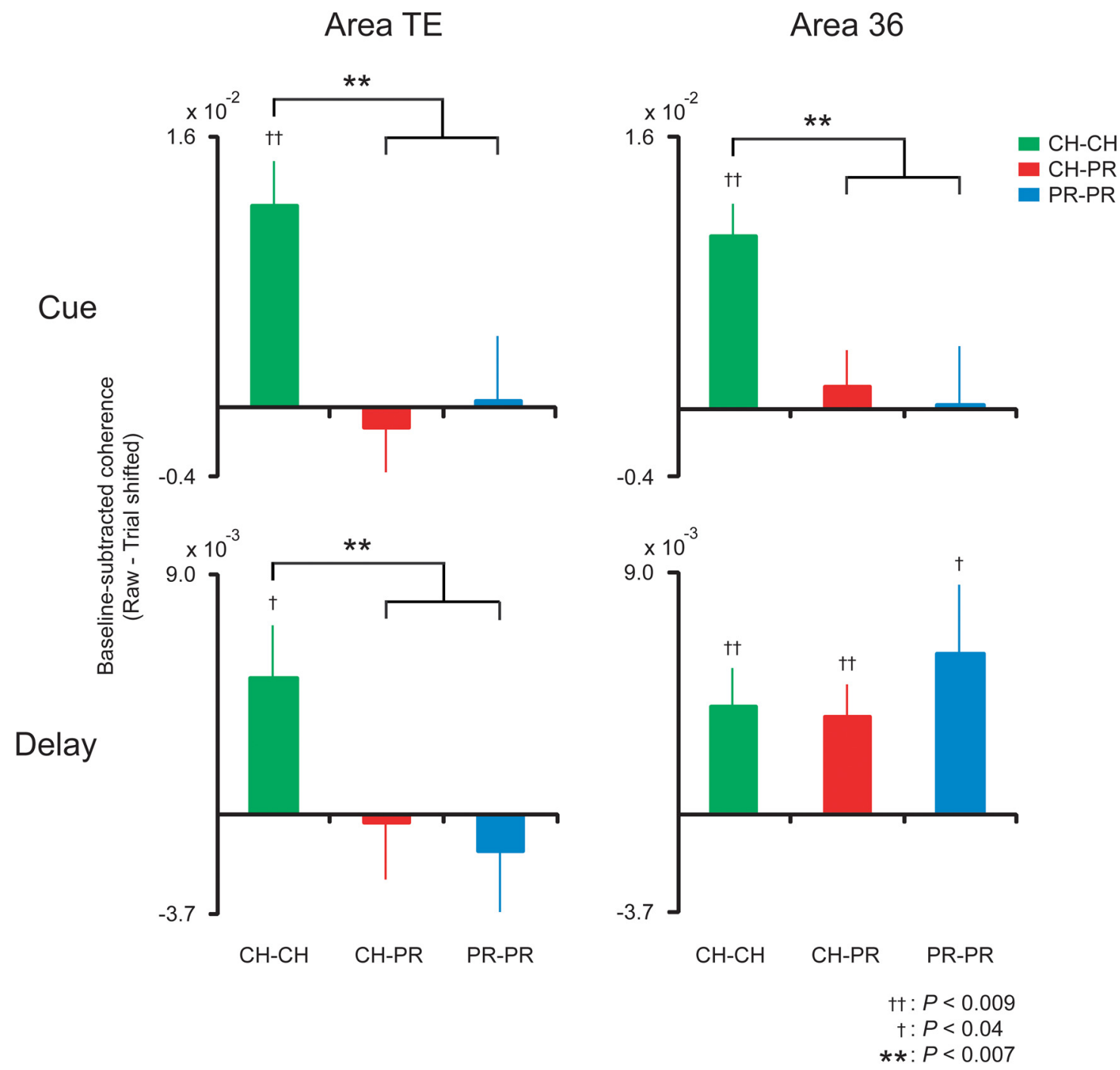

Figure 5. Functional coupling between memory neurons during the cue and delay periods. Gamma coherence for the optimal stimulus was calculated between $\mathrm{CH}$ neurons ( $\mathrm{CH}-\mathrm{CH}$, green), PR neurons (PR-PR, blue), and their combinations (CH-PR, red) in areas TE (left) and 36 (right) during the cue (top) and delay (bottom) periods. Ordinates depict the increase in the gamma coherence compared with the baseline. The trial-shifted control was presubtracted in calculating the coherence. $†$ and $++C o m p a r i s o n$ with zero. Error bars indicate SEM.

pared with the original, paired $t$ test; $n=70$ and 131 for areas TE and 36, respectively) and was abolished ( $p>0.6$, compared with the trial-shifted control). Coherence for the original cell pairs was also calculated after random eliminations of spikes to attain the same firing rate as the replaced cell (Gregoriou et al., 2009; Verhoef et al., 2011; Dean et al., 2012) and the resultant coherence in both areas remained greater than those for the replaced cell pairs $(p<0.005)$. These results suggest that the observed gamma coherence reflected the specific coupling between neurons in which response selectivity for the optimal stimulus matched with each other. This implies that functional coupling among specific memory neurons was recruited during the delay period depending on the presented cue stimulus (Kohn and Smith, 2005; Ohiorhenuan et al., 2010; Stanley et al., 2012).

\section{Spectral power of individual spike trains and gamma} coherence with putative inhibitory neurons

In addition to the coherence between neurons, we also computed the firing-rate-normalized spectral power for each memory neu- ron and examined the rhythmic property of individual spike trains (Pesaran et al., 2002; Joelving et al., 2007; Lima et al., 2011). During the cue period, spike trains of memory neuron classes in areas TE and 36 that showed significant coherence (i.e., $\mathrm{CH}$ neurons for both areas TE and 36) exhibited significant increase in the gamma power compared with the baseline $(p<0.003$ and $p<0.04$, paired $t$ test, $n=112$ and 107 for areas TE and 36, respectively; Fig. $7 C$, left). Likewise, during the delay period, spike trains of memory neuron classes that showed significant gamma coherence $(\mathrm{CH}$ neurons in area TE; $\mathrm{CH}$ and $\mathrm{PR}$ neurons in area 36) exhibited significant increase in the gamma power $(p<0.003$ and $p<0.02, n=112$ and 166 for areas TE and 36, respectively; Fig. $7 C$, right). In contrast, in the lower-frequency ranges, significant increases in the spectral power were not observed during the cue period $(p>0.3)$. During the delay period, a significant increase of the spectral power was also observed in the alpha- and beta-frequency ranges in area $36(p<$ 0.03 and $p<0.008$ for the alpha and beta ranges, respectively), but not in the theta range in area 36 or in any of the lower frequency ranges in area TE $(p>0.3)$. These results suggest that the coherence 


\section{Neuronal coupling for the optimal pair of stimuli during the delay period}

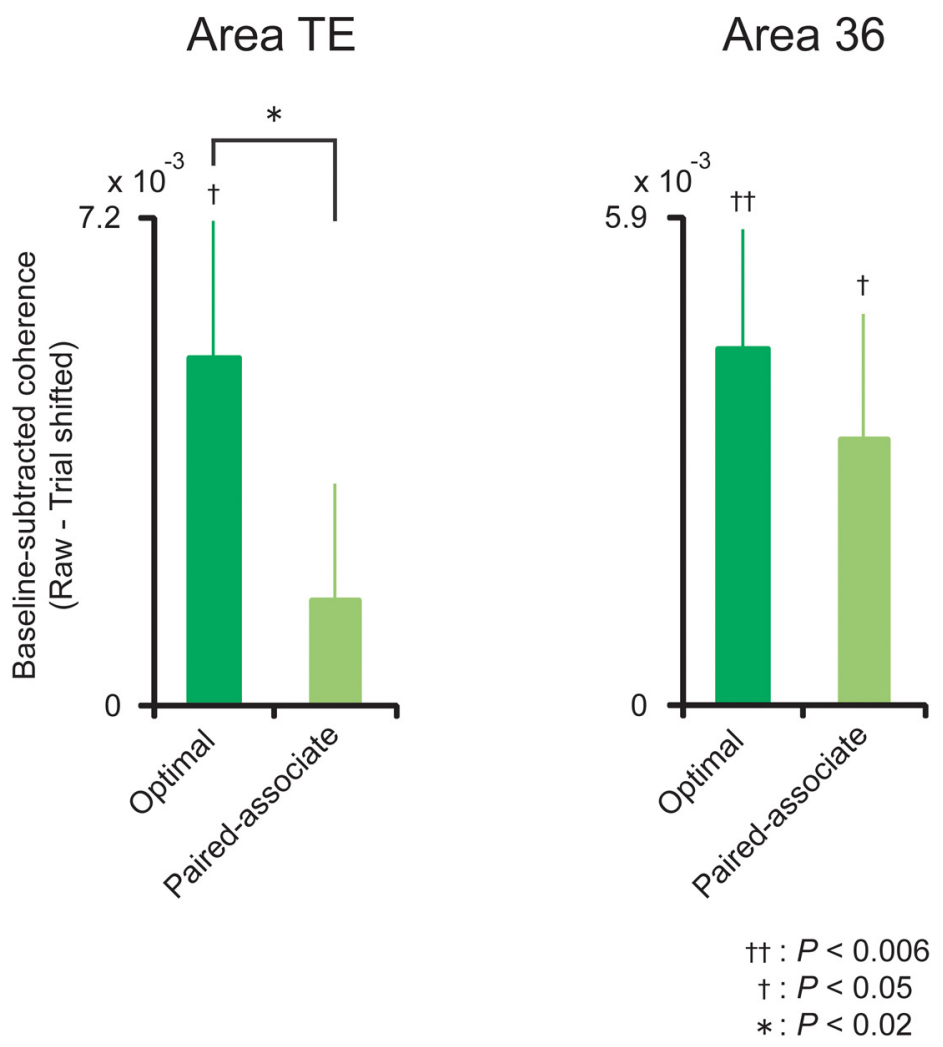

Figure 6. Functional coupling between CH neurons for the optimal pair of stimuli. Gamma coherence during the delay period was calculated between CH neurons for the optimal stimulus (green) and its paired associate (light green) in areas TE (left) and 36 (right). Ordinates depict the increase in the gamma coherence compared with the baseline. The trial-shifted control was presubtracted in calculating the coherence. $†$ and $+\dagger$ Comparison with zero. Error bars indicate SEM.

results in different frequency ranges might be, at least in part, due to the frequency dependence of the spectral power of each constituent neuron.

Finally, the coherence between putative inhibitory and excitatory neurons was also examined (see Materials and Methods). During the cue period, putative inhibitory, cue-selective neurons exhibited significant gamma coherence with putative excitatory $\mathrm{CH}$ neurons in both areas TE and $36(30-80 \mathrm{~Hz}, p<0.03$ and $p<0.002$, paired $t$ test, $n=23$ and $n=17$ for areas TE and 36, respectively). During the delay period, significant gamma coherence between putative inhibitory and excitatory memory neurons was observed in area $36(p<0.04, n=12)$, but not in area $\mathrm{TE}(p>0.4, n=12)$. It should be noted that we intended to record from putative excitatory neurons during the recording sessions. In addition, the number of cortical inhibitory neurons was much smaller than that of excitatory neurons. The resultant number of putative inhibitory neurons in our dataset became much smaller than that of putative excitatory neurons, presumably for these reasons. Therefore, coherence with putative inhibitory neurons remains an important issue for future studies.

\section{Discussion}

In this study, we simultaneously recorded from multiple singleunits in areas TE and 36 of the AIT cortex while monkeys performed an object association memory task and examined the interactions between memory neurons during the delay period. Although neurons coding for the cue stimulus ( $\mathrm{CH}$ neurons) interacted with each other in both areas, functional coupling in- volving neurons that coded for the to-be-recalled target (PR neurons) emerged only in area 36 during memory retrieval. Furthermore, pairs of $\mathrm{CH}$ neurons only in area 36 exhibited functional coupling in response to a learned association of objects during memory retention. Together, these results suggest predominant interactions of memory neurons in area 36 during the mnemonic processing, which may underlie the crucial role of this brain area in both storage and retrieval of object association memory.

\section{Gamma coherence as a measure of neuronal coupling within a cortical microcircuit}

Coherence has been used as a measure of interactions between spiking neurons (Lee, 2003; Saalmann et al., 2007; Fries et al., 2008; Sirota et al., 2008; Zhou et al., 2008; Gregoriou et al., 2009; Hirabayashi et al., 2010; Lima et al., 2011; Verhoef et al., 2011; Hirabayashi et al., 2013b). The amplitude of the coherence between single-unit activities, especially in the gamma-frequency range, has been shown to correspond with the peak height of the cross-correlogram within a time lag of several milliseconds (Zhou et al., 2008; Hirabayashi et al., 2010). The gamma coherence during the delay period observed in the present study, therefore, likely reflects synaptic interactions among the network of memory neurons in the AIT cortex. It should be noted, however, that the coherence or cross-correlation between single-unit activities does not merely reflect anatomical connections between the neurons; they can be also affected by the activity of the neuronal 


\section{Phase variance of coherence during during the delay period}

A

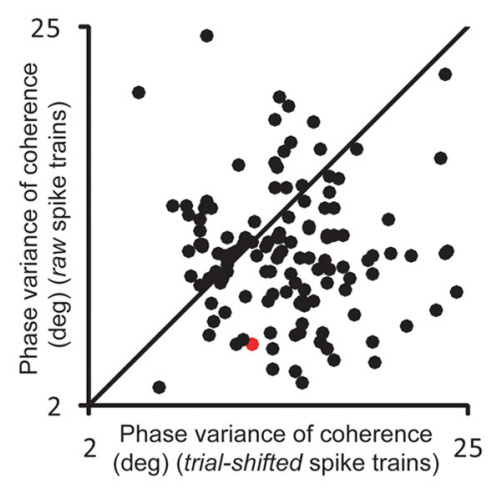

B

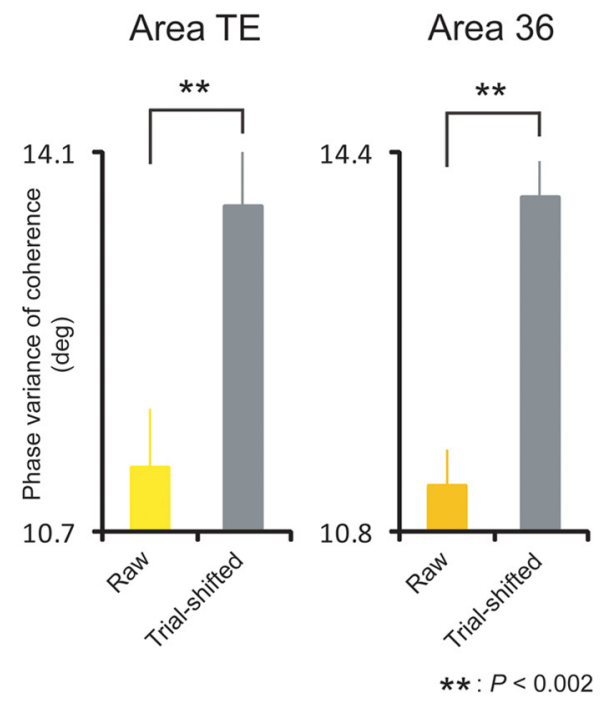

C

Gamma power of spike trains

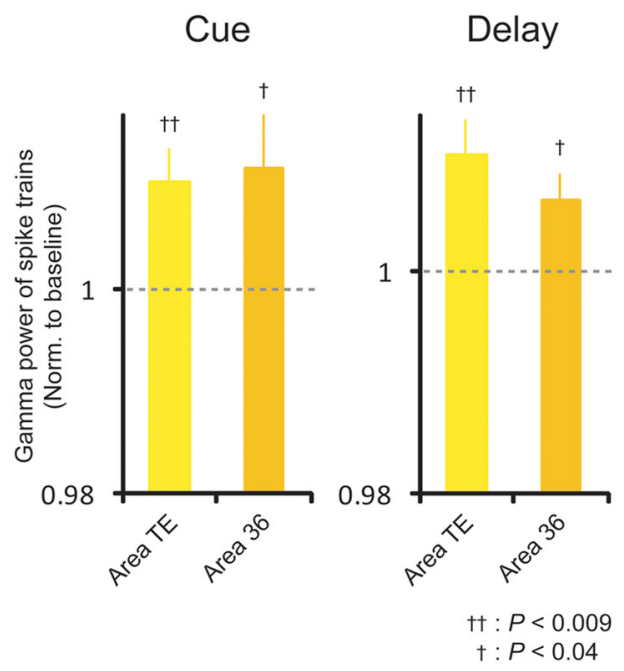

Figure 7. Phase consistency of gamma coherence and gamma power of spike trains for the constituent memory neurons. $A$, Scatter plot of the phase variance (see Materials and Methods) of the gamma coherence during the delay period for the raw (ordinate) and trial-shifted (abscissa) spike trains of memory neuron pairs in area 36. Red dot indicates the cell pair depicted in Figure 2. B, Phase variance of the coherence during the delay period for the raw (yellow for area TE, orange for area 36) and trial-shifted (gray) spike trains of memory neurons. Error bars indicate SEM. C, Firing-rate-normalized gamma power of spike trains for memory neurons in areas TE (yellow) and 36 (orange) during the cue (left) and delay (right) periods. Gamma power was normalized to the baseline. $\uparrow$ and + Comparison with baseline. Error bars indicate SEM. network in which the recorded pair of neurons is embedded (Ostojic et al., 2009; Havenith et al., 2011; Yu and Ferster, 2013).

Neuronal firing exerts an impact on the postsynaptic neurons collectively in concert with many other neurons. Even a small difference in the firing rate at the single neuron level thus could be a robust signal on the next stage as a population. The coherence value between single neurons has been suggested to be smaller than that between LFPs or multiunit activities (Zeitler et al., 2006; Gregoriou et al., 2009). Coherence between single neurons examined in the present study probably represents only a part of interactions among the neuronal population participating in the processing, so even a small value would suggest a nontrivial impact as a whole network of neurons.

In this study, neuronal interactions were explored in a cortical microcircuit within a spatial range of $\sim 300 \mu \mathrm{m}$ (Buzsáki, 2004). Microcircuits within this spatial range have been shown to exhibit several intriguing properties compared with neurons separated by longer distances, including a higher probability of neuronal coupling (Das and Gilbert, 1999; Constantinidis et al., 2001; Sakurai and Takahashi, 2006; Atencio and Schreiner, 2013) and stimulusdependent interactions among more than triplets of neurons (Ohiorhenuan et al., 2010). Therefore, the neuronal coupling we found might be most prominent within the local vicinity. However, the cortical laminar circuitry, especially between supragranular and infragranular layers, suggests the importance of interactions with more distant neurons in cortical computations (Yoshimura et al., 2005; Takeuchi et al., 2011; Opris et al., 2012). Whether the increased coherence can be also observed between a distant pair of neurons that share similar response selectivity is therefore an important issue for future studies.

\section{Relationships between the neuronal coupling and delay activity}

Delay activities of cortical neurons are thought to underlie mnemonic processing such as retainment of the presented stimulus information and retrieval of the target (Fuster and Jervey, 1981; Chafee and Goldman-Rakic, 1998; Erickson and Desimone, 1999; Rainer et al., 1999; Romo et al., 1999; Curtis and D’Esposito, 2003; Miyashita, 2004; Freedman and Assad, 2006). These neuronal activities during the period without a sensory stimulus probably need to be driven by inputs 
from other neurons, and recurrent neuronal interaction has been postulated as a candidate for the input source (Hebb, 1949; Wang, 2001; Brunel, 2003, but see also Egorov et al., 2002). However, only a few studies have provided empirical data for the interactions between single neurons during the delay period of a memory task (Sakurai and Takahashi, 2006; Katsuki and Constantinidis, 2013; Wang et al., 2013). The present results of neuronal coupling during the delay period (Fig. 5, bottom), which depended on selectivity matching between the constituent neurons, support this hypothesis. In addition, functional coupling even during the cue period was stronger for cell pairs that exhibited stimulus-selective firings during the delay period (Fig. 4). This result is also consistent with the presumed close relationships between functional coupling and the delay activities of the constituent neurons (Wang, 2001; Brunel, 2003; Wang et al., 2013). It should be noted, however, that we also found that coupling with PR neurons differed substantially between areas TE and 36 during the delay period (Fig. 5, bottom), even though their firing rates were comparable. This result suggests that the driving source of the delay activity is not limited to local interactions.

Previously, we investigated whether the delay activity of AIT neurons persists after the presentation of distracting stimuli in an object association memory task (Takeda et al., 2005). Monkeys were trained to perform a modified version of this task in which distractor stimuli interrupted the delay epoch between the cue and target stimuli. For each neuron, information about each stimulus conveyed by the delay activity was estimated as a coefficient of multiple regression analysis. We found that target information derived from long-term memory persisted despite the distractors. Therefore, the coupling observed in the present study, at least between PR neurons in area 36, would persist if a similar visual interruption were introduced and these couplings might be related to the active recall process (Takeda et al., 2005). Further experiments are needed to determine whether the interactions involving $\mathrm{CH}$ neurons also retain with intervening stimuli or if neuronal coupling increases during passive viewing.

\section{Neuronal interactions in the lower-frequency ranges}

During the delay period, functional coupling between memory neurons was observed in the gamma frequency range in both areas TE and 36 (Fig. 5, bottom), but was not observed in the lower-frequency ranges in either area. These results are consistent with previous studies showing that the neuronal interactions in the gamma range are observed in a local network (Fries et al., 2008; Zhou et al., 2008; Hirabayashi et al., 2010; see also Gregoriou et al., 2009). However, low-frequency interactions, especially during the delay period, might be detectable only in LFPs. It has been shown that the amplitude of LFP gamma power is modulated by the phase of low-frequency components (Canolty et al., 2006; Tort et al., 2008; Colgin et al., 2009; Fujisawa and Buzsáki, 2011; Igarashi et al., 2013; Lisman and Jensen, 2013; van Wingerden et al., 2014). Therefore, the observed gamma-range interactions might couple with low-frequency LFPs around those neurons (Fujisawa and Buzsáki, 2011; Bosman et al., 2012).

\section{Relationships between memory retrieval signals in areas TE and 36}

Recently, we demonstrated that $\mathrm{CH}$ neurons exhibit causal influence on the activity of PR neurons during memory retrieval in area 36 (Hirabayashi et al., 2013b). In the present study, coupling between $\mathrm{CH}$ and $\mathrm{PR}$ neurons occurred in area 36, but not in area TE (Fig. 5). Combined with the previous results, therefore, al- though recall activities were evident in both areas TE and 36 (Fig. 3 ), these activities might be generated through microcircuit operations in area 36, but not in area TE. Anatomical studies have shown that neurons in areas TE and 36 are densely interconnected (Suzuki and Amaral, 1994; Saleem and Tanaka, 1996). Furthermore, it was shown that visual responses of area TE neurons preceded those of area 36 neurons consistently with the anatomical hierarchy, whereas recall activities of area 36 neurons emerged earlier than those of area TE neurons, suggesting that the retrieval signal of area TE neurons was transmitted from area 36 (Naya et al., 2001). The present findings support this hypothesis in terms of distinct neuronal coupling in these areas.

The present study compared microcircuits between the hierarchically distinct, successive areas TE and 36 of the macaque AIT cortex in the paradigm of an object association memory task, and demonstrated predominant neuronal interactions in area 36 during the mnemonic processing of object association. To understand the whole picture of neuronal mechanisms underlying the storage and retrieval of associative object memory, it would be necessary to link these microcircuits with laminar circuits and inter-area networks (Brovelli et al., 2004; Paz et al., 2006; Pesaran et al., 2008; Sirota et al., 2008; Colgin et al., 2009; Gregoriou et al., 2009; Verhoef et al., 2011; Bosman et al., 2012; Liebe et al., 2012; Saalmann et al., 2012; Salazar et al., 2012) to build a unified framework in future studies.

\section{References}

Atencio CA, Schreiner CE (2013) Auditory cortical local subnetworks are characterized by sharply synchronous activity. J Neurosci 33:1850318514. CrossRef Medline

Bokil H, Andrews P, Kulkarni JE, Mehta S, Mitra PP (2010) Chronux: a platform for analyzing neural signals. J Neurosci Methods 192:146-151. CrossRef Medline

Bollimunta A, Chen Y, Schroeder CE, Ding M (2008) Neuronal mechanisms of cortical alpha oscillations in awake-behaving macaques. J Neurosci 28:9976-9988. CrossRef Medline

Bollimunta A, Mo J, Schroeder CE, Ding M (2011) Neuronal mechanisms and attentional modulation of corticothalamic alpha oscillations. J Neurosci 31:4935-4943. CrossRef Medline

Bosman CA, Schoffelen JM, Brunet N, Oostenveld R, Bastos AM, Womelsdorf T, Rubehn B, Stieglitz T, De Weerd P, Fries P (2012) Attentional stimulus selection through selective synchronization between monkey visual areas. Neuron 75:875-888. CrossRef Medline

Brovelli A, Ding M, Ledberg A, Chen Y, Nakamura R, Bressler SL (2004) Beta oscillations in a large-scale sensorimotor cortical network: directional influences revealed by Granger causality. Proc Natl Acad Sci U S A 101:9849-9854. CrossRef Medline

Brunel N (2003) Dynamics and plasticity of stimulus-selective persistent activity in cortical network models. Cereb Cortex 13:1151-1161. CrossRef Medline

Buckley MJ, Gaffan D, Murray EA (1997) Functional double dissociation between two inferior temporal cortical areas: perirhinal cortex versus middle temporal gyrus. J Neurophysiol 77:587-598. Medline

Buffalo EA, Ramus SJ, Clark RE, Teng E, Squire LR, Zola SM (1999) Dissociation between the effects of damage to perirhinal cortex and area TE. Learn Mem 6:572-599. CrossRef Medline

Buschman TJ, Miller EK (2007) Top-down versus bottom-up control of attention in the prefrontal and posterior parietal cortices. Science 315: 1860-1862. CrossRef Medline

Buzsáki G (2004) Large-scale recording of neuronal ensembles. Nat Neurosci 7:446-451. CrossRef Medline

Buzsáki G, Moser EI (2013) Memory, navigation and theta rhythm in the hippocampal-entorhinal system. Nat Neurosci 16:130-138. CrossRef Medline

Canolty RT, Edwards E, Dalal SS, Soltani M, Nagarajan SS, Kirsch HE, Berger MS, Barbaro NM, Knight RT (2006) High gamma power is phaselocked to theta oscillations in human neocortex. Science 313:1626-1628. CrossRef Medline

Chafee MV, Goldman-Rakic PS (1998) Matching patterns of activity in pri- 
mate prefrontal area 8a and parietal area 7ip neurons during a spatial working memory task. J Neurophysiol 79:2919-2940. Medline

Colgin LL, Denninger T, Fyhn M, Hafting T, Bonnevie T, Jensen O, Moser MB, Moser EI (2009) Frequency of gamma oscillations routes flow of information in the hippocampus. Nature 462:353-357. CrossRef Medline

Constantinidis C, Franowicz MN, Goldman-Rakic PS (2001) Coding specificity in cortical microcircuits: a multiple-electrode analysis of primate prefrontal cortex. J Neurosci 21:3646-3655. Medline

Curtis CE, D'Esposito M (2003) Persistent activity in the prefrontal cortex during working memory. Trends Cogn Sci 7:415-423. CrossRef Medline

Das A, Gilbert CD (1999) Topography of contextual modulations mediated by short-range interactions in primary visual cortex. Nature 399:655661. CrossRef Medline

Dean HL, Hagan MA, Pesaran B (2012) Only coherent spiking in posterior parietal cortex coordinates looking and reaching. Neuron 73:829-841. CrossRef Medline

DeCoteau WE, Thorn C, Gibson DJ, Courtemanche R, Mitra P, Kubota Y, Graybiel AM (2007) Learning-related coordination of striatal and hippocampal theta rhythms during acquisition of a procedural maze task. Proc Natl Acad Sci U S A 104:5644-5649. CrossRef Medline

Egorov AV, Hamam BN, Fransén E, Hasselmo ME, Alonso AA (2002) Graded persistent activity in entorhinal cortex neurons. Nature 420:173178. CrossRef Medline

Erickson CA, Desimone R (1999) Responses of macaque perirhinal neurons during and after visual stimulus association learning. J Neurosci 19: 10404-10416. Medline

Freedman DJ, Assad JA (2006) Experience-dependent representation of visual categories in parietal cortex. Nature 443:85-88. CrossRef Medline

Fries P, Womelsdorf T, Oostenveld R, Desimone R (2008) The effects of visual stimulation and selective visual attention on rhythmic neuronal synchronization in macaque area V4. J Neurosci 28:4823-4835. CrossRef Medline

Fujisawa S, Buzsáki G (2011) A 4 Hz oscillation adaptively synchronizes prefrontal, VTA, and hippocampal activities. Neuron 72:153-165. CrossRef Medline

Fuster JM, Jervey JP (1981) Inferotemporal neurons distinguish and retain behaviorally relevant features of visual stimuli. Science 212:952-955. CrossRef Medline

Gregoriou GG, Gotts SJ, Zhou H, Desimone R (2009) High-frequency, long-range coupling between prefrontal and visual cortex during attention. Science 324:1207-1210. CrossRef Medline

Havenith MN, Yu S, Biederlack J, Chen NH, Singer W, Nikolić D (2011) Synchrony makes neurons fire in sequence, and stimulus properties determine who is ahead. J Neurosci 31:8570-8584. CrossRef Medline

Hebb DO (1949) The organization of behavior: a neuropsychological theory. New York: John Wiley and Sons.

Hirabayashi T, Miyashita Y (2005) Dynamically modulated spike correlation in monkey inferior temporal cortex depending on the feature configuration within a whole object. J Neurosci 25:10299-10307. CrossRef Medline

Hirabayashi T, Miyashita Y (2014) Computational principles of microcircuits for visual object processing in the macaque temporal cortex. Trends Neurosci 37:178-187. CrossRef Medline

Hirabayashi T, Takeuchi D, Tamura K, Miyashita Y (2010) Triphasic dynamics of stimulus-dependent information flow between single neurons in macaque inferior temporal cortex. J Neurosci 30:10407-10421. CrossRef Medline

Hirabayashi T, Takeuchi D, Tamura K, Miyashita Y (2013a) Microcircuits for hierarchical elaboration of object coding across primate temporal areas. Science 341:191-195. CrossRef Medline

Hirabayashi T, Takeuchi D, Tamura K, Miyashita Y (2013b) Functional microcircuit recruited during retrieval of object association memory in monkey perirhinal cortex. Neuron 77:192-203. CrossRef Medline

Igarashi J, Isomura Y, Arai K, Harukuni R, Fukai T (2013) A theta-gamma oscillation code for neuronal coordination during motor behavior. J Neurosci 33:18515-18530. CrossRef Medline

Jarvis MR, Mitra PP (2001) Sampling properties of the spectrum and coherency of sequences of action potentials. Neural Comput 13:717-749. Medline

Jensen O, Colgin LL (2007) Cross-frequency coupling between neuronal oscillations. Trends Cogn Sci 11:267-269. CrossRef Medline

Joelving FC, Compte A, Constantinidis C (2007) Temporal properties of posterior parietal neuron discharges during working memory and passive viewing. J Neurophysiol 97:2254-2266. CrossRef Medline

Judge SJ, Richmond BJ, Chu FC (1980) Implantation of magnetic search coils for measurement of eye position: an improved method. Vision Res 20:535-538. CrossRef Medline

Jutras MJ, Fries P, Buffalo EA (2009) Gamma-band synchronization in the macaque hippocampus and memory formation. J Neurosci 29:1252112531. CrossRef Medline

Kahana MJ (2006) The cognitive correlates of human brain oscillations. J Neurosci 26:1669-1672. CrossRef Medline

Katsuki F, Constantinidis C (2013) Time course of functional connectivity in primate dorsolateral prefrontal and posterior parietal cortex during working memory. PloS One 8:e81601. CrossRef Medline

Kohn A, Smith MA (2005) Stimulus dependence of neuronal correlation in primary visual cortex of the macaque. J Neurosci 25:3661-3673. CrossRef Medline

Lashgari R, Li X, Chen Y, Kremkow J, Bereshpolova Y, Swadlow HA, Alonso JM (2012) Response properties of local field potentials and neighboring single neurons in awake primary visual cortex. J Neurosci 32:1139611413. CrossRef Medline

Lee D (2003) Coherent oscillations in neuronal activity of the supplementary motor area during a visuomotor task. J Neurosci 23:6798-6809. Medline

Lee H, Simpson GV, Logothetis NK, Rainer G (2005) Phase locking of single neuron activity to theta oscillations during working memory in monkey extrastriate visual cortex. Neuron 45:147-156. CrossRef Medline

Lee JH, Whittington MA, Kopell NJ (2013) Top-down beta rhythms support selective attention via interlaminar interaction: a model. PLoS Comput Biol 9:e1003164. CrossRef Medline

Liebe S, Hoerzer GM, Logothetis NK, Rainer G (2012) Theta coupling between V4 and prefrontal cortex predicts visual short-term memory performance. Nat Neurosci 15:456-462, S1-S2. CrossRef Medline

Lima B, Singer W, Neuenschwander S (2011) Gamma responses correlate with temporal expectation in monkey primary visual cortex. J Neurosci 31:15919-15931. CrossRef Medline

Lisman JE, Jensen O (2013) The theta-gamma neural code. Neuron 77: 1002-1016. CrossRef Medline

Liu Z, Richmond BJ (2000) Response differences in monkey TE and perirhinal cortex: stimulus association related to reward schedules. J Neurophysiol 83:1677-1692. Medline

Logothetis NK, Sheinberg DL (1996) Visual object recognition. Annu Rev Neurosci 19:577-621. CrossRef Medline

Matsui T, Koyano KW, Koyama M, Nakahara K, Takeda M, Ohashi Y, Naya Y, Miyashita Y (2007) MRI-based localization of electrophysiological recording sites within the cerebral cortex at single-voxel accuracy. Nat Methods 4:161-168. CrossRef Medline

Messinger A, Squire LR, Zola SM, Albright TD (2001) Neuronal representations of stimulus associations develop in the temporal lobe during learning. Proc Natl Acad Sci U S A 98:12239-12244. CrossRef Medline

Mishkin M, Suzuki WA, Gadian DG, Vargha-Khadem F (1997) Hierarchical organization of cognitive memory. Philos Trans R Soc Lond B Biol Sci 352:1461-1467. CrossRef Medline

Mitchell JF, Sundberg KA, Reynolds JH (2007) Differential attentiondependent response modulation across cell classes in macaque visual area V4. Neuron 55:131-141. CrossRef Medline

Miyashita Y (1988) Neuronal correlate of visual associative long-term memory in the primate temporal cortex. Nature 335:817-820. CrossRef Medline

Miyashita Y (2004) Cognitive memory: cellular and network machineries and their top-down control. Science 306:435-440. CrossRef Medline

Naya Y, Yoshida M, Miyashita Y (2001) Backward spreading of memoryretrieval signal in the primate temporal cortex. Science 291:661-664. CrossRef Medline

Naya Y, Yoshida M, Miyashita Y (2003a) Forward processing of long-term associative memory in monkey inferotemporal cortex. J Neurosci 23: 2861-2871. Medline

Naya Y, Yoshida M, Takeda M, Fujimichi R, Miyashita Y (2003b) Delayperiod activities in two subdivisions of monkey inferotemporal cortex during pair association memory task. Eur J Neurosci 18:2915-2918. CrossRef Medline

Ohiorhenuan IE, Mechler F, Purpura KP, Schmid AM, Hu Q, Victor JD 
(2010) Sparse coding and high-order correlations in fine-scale cortical networks. Nature 466:617-621. CrossRef Medline

Ojemann GA, Ojemann J, Ramsey NF (2013) Relation between functional magnetic resonance imaging (fMRI) and single neuron, local field potential (LFP) and electrocorticography (ECoG) activity in human cortex. Front Hum Neurosci 7:34. CrossRef Medline

Opris I, Hampson RE, Gerhardt GA, Berger TW, Deadwyler SA (2012) Columnar processing in primate $\mathrm{pFC}$ : evidence for executive control microcircuits. J Cogn Neurosci 24:2334-2347. CrossRef Medline

Osada T, Adachi Y, Kimura HM, Miyashita Y (2008) Towards understanding of the cortical network underlying associative memory. Philos Trans R Soc Lond B Biol Sci 363:2187-2199. CrossRef Medline

Ostojic S, Brunel N, Hakim V (2009) How connectivity, background activity, and synaptic properties shape the cross-correlation between spike trains. J Neurosci 29:10234-10253. CrossRef Medline

Paz R, Pelletier JG, Bauer EP, Paré D (2006) Emotional enhancement of memory via amygdala-driven facilitation of rhinal interactions. Nat Neurosci 9:1321-1329. CrossRef Medline

Pesaran B, Pezaris JS, Sahani M, Mitra PP, Andersen RA (2002) Temporal structure in neuronal activity during working memory in macaque parietal cortex. Nat Neurosci 5:805-811. CrossRef Medline

Pesaran B, Nelson MJ, Andersen RA (2008) Free choice activates a decision circuit between frontal and parietal cortex. Nature 453:406-409. CrossRef Medline

Rainer G, Rao SC, Miller EK (1999) Prospective coding for objects in primate prefrontal cortex. J Neurosci 19:5493-5505. Medline

Romo R, Brody CD, Hernández A, Lemus L (1999) Neuronal correlates of parametric working memory in the prefrontal cortex. Nature 399:470473. CrossRef Medline

Roy SA, Alloway KD (2001) Coincidence detection or temporal integration? What the neurons in somatosensory cortex are doing. J Neurosci 21: 2462-2473. Medline

Saalmann YB, Pigarev IN, Vidyasagar TR (2007) Neural mechanisms of visual attention: how top-down feedback highlights relevant locations. Science 316:1612-1615. CrossRef Medline

Saalmann YB, Pinsk MA, Wang L, Li X, Kastner S (2012) The pulvinar regulates information transmission between cortical areas based on attention demands. Science 337:753-756. CrossRef Medline

Sakai K, Miyashita Y (1991) Neural organization for the long-term memory of paired associates. Nature 354:152-155. CrossRef Medline

Sakurai Y, Takahashi S (2006) Dynamic synchrony of firing in the monkey prefrontal cortex during working-memory tasks. J Neurosci 26:1014110153. CrossRef Medline

Salazar RF, Dotson NM, Bressler SL, Gray CM (2012) Content-specific fronto-parietal synchronization during visual working memory. Science 338:1097-1100. CrossRef Medline

Saleem KS, Tanaka K (1996) Divergent projections from the anterior inferotemporal area TE to the perirhinal and entorhinal cortices in the macaque monkey. J Neurosci 16:4757-4775. Medline

Sirota A, Montgomery S, Fujisawa S, Isomura Y, Zugaro M, Buzsáki G (2008) Entrainment of neocortical neurons and gamma oscillations by the hippocampal theta rhythm. Neuron 60:683-697. CrossRef Medline

Squire LR, Zola-Morgan S (1991) The medial temporal lobe memory system. Science 253:1380-1386. CrossRef Medline

Stanley GB, Jin J, Wang Y, Desbordes G, Wang Q, Black MJ, Alonso JM (2012) Visual orientation and directional selectivity through thalamic synchrony. J Neurosci 32:9073-9088. CrossRef Medline

Suzuki WA (2010) Untangling memory from perception in the medial temporal lobe. Trends Cogn Sci 14:195-200. CrossRef Medline

Suzuki WA, Amaral DG (1994) Perirhinal and parahippocampal cortices of the macaque monkey: cortical afferents. J Comp Neurol 350:497-533. CrossRef Medline

Takeda M, Naya Y, Fujimichi R, Takeuchi D, Miyashita Y (2005) Active maintenance of associative mnemonic signal in monkey inferior temporal cortex. Neuron 48:839-848. CrossRef Medline

Takeuchi D, Hirabayashi T, Tamura K, Miyashita Y (2011) Reversal of interlaminar signal between sensory and memory processing in monkey temporal cortex. Science 331:1443-1447. CrossRef Medline

Tallon-Baudry C, Bertrand O, Hénaff MA, Isnard J, Fischer C (2005) Attention modulates gamma-band oscillations differently in the human lateral occipital cortex and fusiform gyrus. Cereb Cortex 15:654-662. CrossRef Medline

Tomita H, Ohbayashi M, Nakahara K, Hasegawa I, Miyashita Y (1999) Topdown signal from prefrontal cortex in executive control of memory retrieval. Nature 401:699-703. CrossRef Medline

Tort AB, Kramer MA, Thorn C, Gibson DJ, Kubota Y, Graybiel AM, Kopell NJ (2008) Dynamic cross-frequency couplings of local field potential oscillations in rat striatum and hippocampus during performance of a T-maze task. Proc Natl Acad Sci U S A 105:20517-20522. CrossRef Medline

Usrey WM, Alonso JM, Reid RC (2000) Synaptic interactions between thalamic inputs to simple cells in cat visual cortex. J Neurosci 20:5461-5467. Medline

van Wingerden M, van der Meij R, Kalenscher T, Maris E, Pennartz CM (2014) Phase-amplitude coupling in rat orbitofrontal cortex discriminates between correct and incorrect decisions during associative learning. J Neurosci 34:493-505. CrossRef Medline

Verhoef BE, Vogels R, Janssen P (2011) Synchronization between the end stages of the dorsal and the ventral visual stream. J Neurophysiol 105: 2030-2042. CrossRef Medline

Vyazovskiy VV, Tobler I (2005) Theta activity in the waking EEG is a marker of sleep propensity in the rat. Brain Res 1050:64-71. CrossRef Medline

Wang M, Yang Y, Wang CJ, Gamo NJ, Jin LE, Mazer JA, Morrison JH, Wang XJ, Arnsten AF (2013) NMDA receptors subserve persistent neuronal firing during working memory in dorsolateral prefrontal cortex. Neuron 77:736-749. CrossRef Medline

Wang XJ (2001) Synaptic reverberation underlying mnemonic persistent activity. Trends Neurosci 24:455-463. CrossRef Medline

Ward LM (2003) Synchronous neural oscillations and cognitive processes. Trends Cogn Sci 7:553-559. CrossRef Medline

Woloszyn L, Sheinberg DL (2012) Effects of long-term visual experience on responses of distinct classes of single units in inferior temporal cortex. Neuron 74:193-205. CrossRef Medline

Womelsdorf T, Schoffelen JM, Oostenveld R, Singer W, Desimone R, Engel AK, Fries P (2007) Modulation of neuronal interactions through neuronal synchronization. Science 316:1609-1612. CrossRef Medline

Xiang JZ, Brown MW (1998) Differential neuronal encoding of novelty, familiarity and recency in regions of the anterior temporal lobe. Neuropharmacology 37:657-676. CrossRef Medline

Yoshida M, Naya Y, Miyashita Y (2003) Anatomical organization of forward fiber projections from area TE to perirhinal neurons representing visual long-term memory in monkeys. Proc Natl Acad Sci U S A 100: 4257-4262. CrossRef Medline

Yoshimura Y, Dantzker JL, Callaway EM (2005) Excitatory cortical neurons form fine-scale functional networks. Nature 433:868-873. CrossRef Medline

Yu J, Ferster D (2013) Functional coupling from simple to complex cells in the visually driven cortical circuit. J Neurosci 33:18855-18866. CrossRef Medline

Zeitler M, Fries P, Gielen S (2006) Assessing neuronal coherence with single-unit, multi-unit, and local field potentials. Neural Comput 18: 2256-2281. CrossRef Medline

Zhou Z, Bernard MR, Bonds AB (2008) Deconstruction of spatial integrity in visual stimulus detected by modulation of synchronized activity in cat visual cortex. J Neurosci 28:3759-3768. CrossRef Medline 